\title{
Generic drugs for developing nations
}

\section{Karolina Maciag and Sandeep P. Kishore}

We applaud the recent editorial (A step in the right direction. Nature Rev. Microbiol. 8, $244(2010))^{1}$ promoting the provision of generics as one of the most effective means of bringing life-saving therapeutics and vaccines to the developing world. Data supporting this claim are mounting. In 2007 alone, for example, the US federal aid agency PEPFAR (President's Emergency Plan for AIDS Relief) saved an estimated US $\$ 64$ million by procurement of generic antiretrovirals. These generics were as little as one-eleventh of the cost of their branded equivalents, regardless of bulk purchasing or differential pricing schemes ${ }^{2}$.

Less than $5 \%$ of pharmaceutical profits are earned in the developing world ${ }^{3}$, and humanitarian global-access licensing promotes generic competition in this tiny slice of the market. This provides an avenue to affordable, life-saving technologies for the millions of people who live on less than $\$ 2$ per day, while sustaining the incentive structure that supports the innovative industry. Surprisingly, universities worldwide have an important role in brokering the world's access to life-saving medical technologies.

In 2001, for instance, Yale University (New Haven, Connecticut, USA) and its licensee Bristol-Myers Squibb (BMS) agreed to let Aspen Pharmaceuticals of Cape Town, South Africa, produce the widely used antiretroviral stavudine (also known as $\mathrm{d} 4 \mathrm{~T}$ ) off patent. This deal triggered a $96 \%$ price reduction of the drug in South Africa with no negative financial effect on Yale or BMS ${ }^{4}$. Momentum from the agreement jump-started the establishment of Universities Allied for Essential Medicines (UAEM), a non-profit organization - of which we are both members consisting of students who work with university administrators to ensure that the fruits of academic research will reach patients in resource-poor nations.

In 2009, six major universities, including Harvard (Cambridge, Massachusetts, USA) and Yale, spearheaded a written commitment to global access to their licensed medical technologies, and this commitment is now endorsed by 23 institutions, including the US National Institutes of Health ${ }^{5}$.
Although this is another step in the right direction, we think that stressing generic manufacture (as was done at Yale in 2001) can and should be the target for universities and publicly funded institutes worldwide. The US Democratic National Convention endorses this view, stating: "We also support the adoption of humanitarian licensing policies that ensure medications developed with the U.S. taxpayer dollars are available off patent in developing countries." (REF. 6.)

A global-access licensing framework, available from $\mathrm{UAEM}^{7}$, is a consensus position that was developed by UAEM in consultation with experts in law, medicine and policy, and it has broad support, including ten Nobel Laureates. We look forward to more discussions on the most sensible and equitable solutions to enabling global access of life-saving treatments for the people in developing nations. Institute of Technology Division of Health Sciences and Technology (HST), Harvard Medical School, 260 Longwood Ave., TMEC 213, Boston, Massachusetts 02115, USA, and the Broad Institute, 7 Cambridge Center, Suite 6112-P, Cambridge, Massachusetts 02142, USA.

Sandeep P. Kishore is at Weill Cornell/Rockefeller/ Sloan-Kettering, 420 East 70th St, Suite 10M, New York, New York 10021, USA.

Correspondence to K.M. e-mail:maciag@post.harvard.edu

1. [No authors listed.] A step in the right direction. Nature Rev. Microbiol. 8, 244 (2010).

2. US Global AIDS Coordinator of the US Department of State. The United States President's emergency plan for AIDS relief. Bringing hope: supplying antiretroviral drugs for HIV/AIDS treatment. US Department of State [online], http://www.state.gov/documents/ organization/66513.pdf (2006).

3. Pharmaceutical Research and Manufacturers of America (PhRMA). Pharmaceutical industry profile 2009. PhRMA [online], http://www.phrma.org/files/ attachments/PhRMA\% 202009\%20Profile\%20 FINAL.pdf (2009).

4. Kapczynski, A., Crone, E. T. \& Merson, M. Global health and university patents. Science 301, 1629 (2003).

5. [No authors listed.] The Ticker: 5 universities to use licensing to provide cheaper drugs to poor and to developing world. The Chronicle of Higher Education (9 Nov 2009).

6. Democratic National Convention Committee. The 2008 Democratic national platform: renewing America's promise. The Democratic Party [online], http://www.democrats.org/a/party/platform.html (2008).

7. UAEM. Global access licensing framework. UAEM [online], http://essentialmedicine.org/sites/default/ files/archive/galf-1-1.pdf (2009).

Competing interests statement

The authors declare no competing financial interests. 